\title{
Transportation Safety for Children with Special Healthcare Needs
}

As guest editors for JPRM, we are pleased to welcome you to this special issue on transportation safety for children with special healthcare needs (CSHCN). A primary focus of this issue is on children who travel in motor vehicles while seated in wheelchairs, but the issue also includes two papers addressing transportation safety issues for small CSHCN who require specially designed child safety seats.

Child passenger safety has been an area of research expertise at the University of Michigan Transportation Research Institute (UMTRI) for over 40 years. In the 1970s UMTRI led the effort to require crash testing of child safety seats (CSS) and have since developed new pediatric crash-test dummies, equipment, and procedures to advance dynamic testing of CSS. UMTRI has also conducted numerous research studies on child anthropometry, pediatric injuries in real-world crashes, CSS design for CSHCN, child belt fit, and CSS misuse patterns and their consequences.

Improving transportation safety for people seated in wheelchairs, or what we commonly refer to as "wheelchair transportation safety (WTS)," is another area that the Biosciences Group at UMTRI has been working to improve for more than 30 years. Our first exposure to this transportation-safety issue came from a concerned individual in Wisconsin who was aware that students were being transported to school with their wheelchairs backed up to the side of the bus so that the students faced the center aisle. The wheelchairs were typically secured to the bus with stretchy elastic cords or mechanical devices that captured the weak and rotating rims of the large wheels of standard weldedframe wheelchairs commonly used in the late 1970s, or by belts wrapped around the wheelchair or around the folding cross bars. There was little consideration for providing effective occupant protection for these students in the event of a school-bus crash.
Since the 1970s, significant progress has been made toward improving the opportunity to provide safe transportation for all people seated in wheelchairs. In large part, this is due to the development and implementation of voluntary industry safety standards for wheelchair tiedown and occupant restraint systems (WTORS) as well as for wheelchairs used as seats in motor vehicles that require dynamic frontal-impact sled-impact testing of these products. Also, in 1992, the National Highway Traffic Safety Administration (NHTSA) published a new and improved version of Federal Motor Vehicle Safety Standard 222: School Bus Passenger Seating and Crash Protection that requires all wheelchair stations installed by school-bus manufacturers to be for forward-facing students, and to provide statically tested four-point, strap-type wheelchair tiedowns and lap/shoulder belt restraints. Today most WTORS on the market and in use comply with the dynamic test requirements of the voluntary industry standard.

However, while the transportation safety standard for wheelchairs, which is known as WC19, has been in place for more than ten years, most wheelchairs in use today do not comply. Moreover, the problem of providing safe transportation for people seated in wheelchairs has been compounded during the past 20 years by dramatic changes in wheelchair designs that make it more difficult to find four accessible points on the wheelchair frame to which tiedown hooks can be effectively attached.

In 2005 and again in 2009, the Rehabilitation Engineering Research Center on Wheelchair Transportation Safety (RERC WTS) convened several state-ofscience (SoS) workshops on WTS involving representatives of stakeholder groups, including wheelchair and WTORS manufacturers, school transportation personnel and other transportation providers, safety researchers, rehabilitation technology suppliers, and con- 
sumers. The goals of these workshops were to identify key obstacles to safe transportation for people with disabilities who travel while seated in wheelchairs as well as key action items that will help to remove these obstacles. A primary obstacle to WTS that was consistently identified in all SoS workshops is the lack of awareness and knowledge of WTS standards, availability of products that comply with these standards, and best practice in using these products when transporting people seated in wheelchairs in motor vehicles. Therefore, it is our hope that this special issue of JPRM will help to reduce these knowledge and awareness gaps in transportation safety for students seated in wheelchairs, and also increase awareness of potential transportation-safety solutions for CSHCN who require modified CSS and/or alternative restraint harness, whether they are traveling in a school bus, a public or paratransit vehicle, or the family van or minivan.

We would like to acknowledge the National Institute on Disability and Rehabilitation Research (NIDRR) that provided support for much of the work presented in this special issue through funding of the RERC WTS over the past ten years under grant numbers H133 E010302 and H133E060064. We encourage readers to visit and explore the RERC WTS website at www. rercwts.org/info and also www.travelsafer.org for more information on providing safe transportation for children and adults who travel seated in their wheelchairs.

Sincerely

Guest Editors

Lawrence W. Schneider, Ph.D.

Research Professor and Associate Director, UMTRI

Director, RERC on Wheelchair Transportation Safety Chair, RESNA Committee on Wheelchairs and

Transportation

Miriam A. Manary, M.S.E. Senior Engineering Research Associate, UMTRI Project Leader, RERC on Wheelchair Transportation Safety

Secretary, RESNA Committee on Wheelchairs and

Transportation E-mail: mmanary@umich.edu 